Forum 2018 · 33:132

https://doi.org/10.1007/s12312-018-0408-1

Online publiziert: 14. März 2018

c) Springer Medizin Verlag $\mathrm{GmbH}$, ein Teil von Springer Nature 2018

\section{Krebsgesellschaft}

Nordrhein-Westfalen e.V.

Die Recherche im Internet gehört mittlerweile obligatorisch dazu, um sich über Krebserkrankungen $\mathrm{zu}$ informieren. Inhalte im Netz sind schnell und rund um die Uhr verfügbar. Das ist bequem, aber es gibt auch viele Fallstricke. Das Netz bietet eine regelrechte Flut an ungefilterten Informationen: darunter qualitativ gute und seriöse Inhalte, aber auch viel Emotionales und „Zweifelhaftes“. Das kann eher verunsichern, als helfen.

Mit einem neuen Ratgeber bietet die Krebsgesellschaft Nordrhein-Westfalen e. V. analoge Unterstützung bei der Informationssuche im Internet. Interessierte finden Tipps was "gute Seiten“ leisten müssen und wie sich zweifelhafte Informationsangebote erkennen lassen. Begriffe der Websprache und die derzeit wichtigsten Internetseiten zum Thema Krebs werden erklärt.

Forum 2018 $\cdot 33: 132-133$

https://doi.org/10.1007/s12312-018-0407-2

Online publiziert: 7. März 2018

(c) Springer Medizin Verlag $\mathrm{GmbH}$, ein Teil von Springer Nature 2018

\section{Berliner}

Krebsgesellschaft e.V.

Durch Wissen zum Leben

Schon wieder ist ein Jahr um und Anmeldungen für Deutschlands größten Frauenlauf gegen Brustkrebs sind bereits mög-

Krebsgesellschaft Nordrhein-Westfalen e.V.

Düsseldorf, Deutschland

\title{
„Krebs im Netz": Neuer Ratgeber unterstützt die Informationssuche im Internet
}

Qualitativ gute Informationen zu Krebs können helfen, dennoch sollten sie nie allein für sich stehen. Vor allem bei Fragen zum individuellen Krankheitsbild ist höchste Vorsicht geboten. Hier sind die behandelnden Ärzte die wichtigsten Ansprechpartner und sollten nicht durch digitale (und analoge) Ratgeber ersetzt werden.

Die Broschüre kann innerhalb von NRW kostenfrei bei der Krebsgesellschaft NRW bestellt werden: online unter www. krebsgesellschaft-nrw.de oder telefonisch 0211/15760990. Die Website bietet ebenfalls die Option, die Broschüre der Krebsgesellschaft NRW als PDF herunterzuladen.

\section{Korrespondenzadresse}

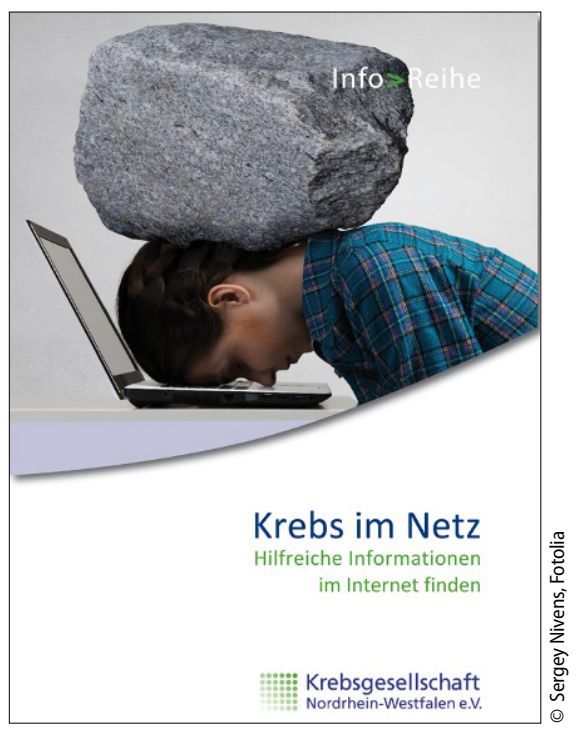

Krebsgesellschaft Nordrhein-Westfalen e.V. Volmerswertherstr. 20, 40221 Düsseldorf, Deutschland

oelschlaeger@krebsgesellschaft-nrw.de
Berliner Krebsgesellschaft e.V.

Berlin, Deutschland

\section{AVON Frauenlauf Berlin: Jetzt anmelden}

\section{Der traditionelle AVON Frauenlauf Berlin findet am 26. Mai statt}

lich. Anmeldeschluss ist der 19. Mai. Der eigentliche Lauf findet am Samstag, den 26. Mai im Berliner Tiergarten und der
Straße des 17. Juni statt. Wie in jedem Jahr wird Sponsor AVON wieder pinkfarbene T-Shirts verteilen, denn der Lauf steht ja 